\title{
Optimization of hinge point in luffing mechanism of aerial working vehicle based on PSO algorithm
}

\author{
Yongjie $\mathrm{Xu}^{1}$, Bangsheng Xing ${ }^{1, *}$, and Lei Cai ${ }^{1}$ \\ ${ }^{1}$ School of Mechanical and Electrical Engineering, Jiangsu Normal University, Xuzhou, China
}

\begin{abstract}
Luffing mechanism is one of the important parts of aerial working vehicle, which plays a decisive role in the overall stability of boom system, the force of luffing cylinder and the force at each hinge point position. In this paper, the five hinge point luffing mechanism of aerial working vehicle is taken as the research object, and the force of its luffing cylinder under dangerous conditions is optimized. By studying the working principle of the boom system and the force analysis of the luffing mechanism, and then establishing the mechanical model, the objective function was optimized based on particle swarm algorithm and Matlab. The optimization results show that the maximum force on the luffing cylinder decreases by $18.9 \%$ with the optimized hinge points, which greatly improves the performance of the whole machine and provides a reference for the application of particle swarm optimization in construction machinery.
\end{abstract}

\section{Introduction}

Aerial working vehicle is a common construction machine for aerial work. Its function is to send workers and instruments to a specified height for maintenance, installation, testing and other work. With the rapid development of China's economy, science and technology, high-altitude working vehicles are attracting more and more attention from enterprises and individual users due to their flexibility, safety, stability, efficiency and wide working face, and they have broad application prospects ${ }^{[1]}$.

The aerial working vehicle is mainly composed of chassis, rotary platform, telescopic boom and luffing system, in which the layout of hinge points in the luffing system will directly affect the performance of the whole machine. At present, the research on the luffing mechanism involves a wide range. Liu Y.B. et al. selected the force of the large boom of the lug mechanism of engineering drilling rig under the most unfavourable working conditions to analyse, and checked its strength through ANSYS to provide a basis for structural optimization design ${ }^{[2]}$. Hu J.P. et al. used the bond-graph theory to conduct modular modelling of key parts of the amplitude modulation mechanism, and established the bond-graph model of the amplitude modulation system by analysing the dynamic characteristics of sub-models, providing reference for analysing and improving the dynamic performance of the amplitude modulation mechanism ${ }^{[3]}$. Xu Y.C. et al. carried out experimental research based on the working principle of the luffing hydraulic system, and put forward an improvement plan according to the testing results, which improve the stability of the hydraulic systems ${ }^{[4]}$. However, there are few researches on the optimization of the hinge points of the luffing mechanism. Traditional design is mainly completed by drawing and calculation to obtain better amplitude performance, but this requires the designer to have rich experience, and there are many shortcomings such as big error, heavy workload and low efficiency.

Based on the working principle of the luffing mechanism, this paper optimizes the position of the hinge points of the luffing mechanism for aerial working vehicles, and its schematic diagram of working range is shown in Figure 1. which came from Xuzhou Handler Special Vehicle Company Ltd. The mechanical model was established to determine the objective function. Finally, particle swarm optimization algorithm was combined to achieve a more reasonable hinge position, which reduced the force on the luffing cylinder and provided ideas for engineers to design the hinge position of the luffing mechanism.

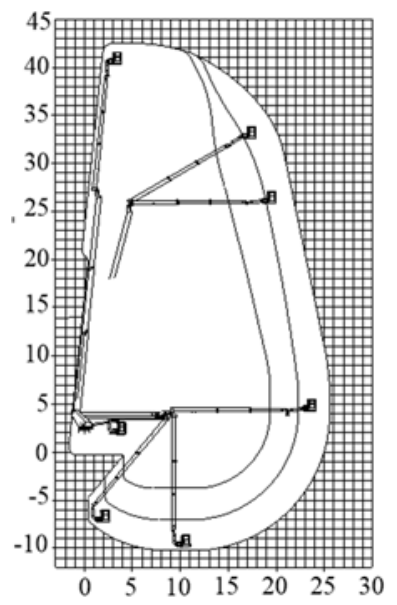

Fig. 1. Schematic diagram of working range of aerial working vehicle

\footnotetext{
* Corresponding author: 6019990415@jsnu.edu.cn
} 


\section{Building mathematical model}

\subsection{Defining design variables}

According to the overall design scheme, the main boom and the secondary boom are in the horizontal position in the initial state $\left(\alpha=0^{\circ}\right)$. The luffing cylinder and both booms are in the full shrinking position with the shortest length. During the entire luffing process, the main boom is extended from $0^{\circ}$ to $84^{\circ}$. At this time, the two booms reach the maximum length, and luffing cylinder of the secondary boom is in a fully extended state. In order to improve the force of the hydraulic cylinder, the position of the hinge point of luffing mechanism of the secondary boom is optimized to achieve the purpose of improving the performance of the whole machine. According to the basic theory of statics and design experience, the target of the optimization is the force of the luffing cylinder under dangerous conditions, when aerial working vehicle reaches the maximum working height.

The simplified mechanical model of the luffing mechanism is shown in Figure 2, where point 1, point 2, point 3 , point 4 , and point 5 represent five hinge points respectively, and the coordinates of each point are $\left(x_{1}, y_{1}\right)$, $\left(x_{2}, y_{2}\right),\left(x_{3}, y_{3}\right),\left(x_{4}, y_{4}\right),\left(x_{5}, y_{5}\right)$. Point $\mathrm{G}$ is the centre of gravity of the folding mechanism, and taking the coordinates of each point as a design variable, the vector is expressed as:

$$
X=\left[x_{1}, y_{1}, x_{2}, y_{2}, x_{3}, y_{3}, x_{4}, y_{4}, x_{5}, y_{5}\right]^{T}
$$

\subsection{Building objective function}

\subsubsection{Thrust calculation of the secondary boom cylinder}

The force analysis of the secondary boom cylinder was carried out, and the luffing mechanism is shown in Figure 2.

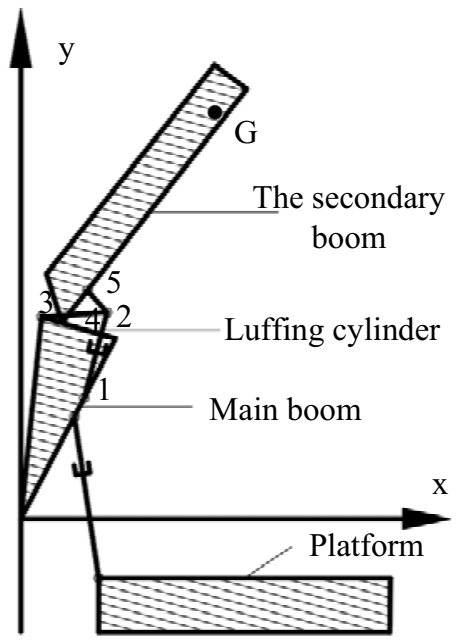

Fig. 2. Schematic diagram of luffing mechanism of aerial work vehicle

It can be known from the moment balance of hinge point 3 ,
That is,

$$
\sum M_{3}=0
$$

In formula:

$$
F_{1} d_{1}-F_{2} d_{2}=0
$$

$F_{1}$ — The force of the secondary boom cylinder, N;

$F_{2} \longrightarrow$ The force of connecting $\operatorname{rod}\left(l_{25}\right), \mathrm{N}$;

$d_{1}$ The arm of force of the secondary boom cylinder to hinge point $3, \mathrm{~mm}$;

$d_{2}$ The arm of force of connecting rod $\left(l_{25}\right)$ to hinge point 3, mm;

\subsubsection{Stress analysis of connecting rod $\left(l_{25}\right)$}

It can be seen from Figure 2 that there is a moment balance for hinge point 4 .

$$
\sum M_{4}=0
$$

That is,

$$
F_{2} d_{4}-G d_{3}=0
$$

In formula:

$\mathrm{G}$ _ Total mass of folding boom and external load, N; $d_{3}$ - The arm of force of the centre of gravity of folding booms and external load to hinge point $4, \mathrm{~mm}$; $d_{4}$ The arm of force of connecting rod $\left(l_{25}\right)$ to hinge point 4, mm;

Deformed by formula (3),

$$
\frac{F_{1}}{F_{2}}=\frac{d_{2}}{d_{1}}
$$

From formulas (3) and (5),

$$
F_{1}=\frac{G d_{2} d_{3}}{d_{1} d_{4}}
$$

Calculating the values of arm of force according to the coordinates of each hinge point, as follows:

$$
\begin{aligned}
& d_{1}=\frac{\left|\left(y_{2}-y_{1}\right) x_{3}-\left(x_{2}-x_{1}\right) y_{3}+\left(y_{1} x_{2}-y_{2} x_{1}\right)\right|}{\sqrt{\left(x_{2}-x_{1}\right)^{2}+\left(y_{2}-y_{1}\right)^{2}}} \\
& d_{2}=\frac{\left|\left(y_{2}-y_{5}\right) x_{3}-\left(x_{2}-x_{5}\right) y_{3}+\left(y_{2} x_{5}-y_{5} x_{2}\right)\right|}{\sqrt{\left(x_{2}-x_{5}\right)^{2}+\left(y_{2}-y_{5}\right)^{2}}} \\
& d_{4}=\frac{\left|\left(y_{2}-y_{5}\right) x_{4}-\left(x_{2}-x_{5}\right) y_{4}+\left(y_{2} x_{5}-y_{5} x_{2}\right)\right|}{\sqrt{\left(x_{2}-x_{5}\right)^{2}+\left(y_{2}-y_{5}\right)^{2}}} \\
& d_{3}=x_{G}-x_{4}
\end{aligned}
$$

It can be known from formulas (6), (7), (8), (9) and (10) that the force of the luffing cylinder of the secondary boom can be determined by the coordinates of each hinge point, as is shown in formula (12).

$$
\begin{aligned}
F_{1} & =\left(x_{1}, y_{1}, x_{2}, y_{2}, x_{3}, y_{3}, x_{4}, y_{4}, x_{5}, y_{5}\right) \\
& =\frac{G\left|\left(y_{2}-y_{5}\right) x_{3}-\left(x_{2}-x_{5}\right) y_{3}+\left(y_{2} x_{5}-y_{5} x_{2}\right)\right|}{\left|\left(y_{2}-y_{1}\right) x_{3}-\left(x_{2}-x_{1}\right) y_{3}+\left(y_{1} x_{2}-y_{2} x_{1}\right)\right|} \\
& \times \frac{\left(x_{G}-x_{4}\right) \times \sqrt{\left(x_{2}-x_{1}\right)^{2}+\left(y_{2}-y_{1}\right)^{2}}}{\left|\left(y_{2}-y_{5}\right) x_{4}-\left(x_{2}-x_{5}\right) y_{4}+\left(y_{2} x_{5}-y_{5} x_{2}\right)\right|}
\end{aligned}
$$

From the formula (12), the force of the luffing cylinder can be adjusted by changing the position of each hinge point, so the formula (12) was chosen as objective function. 


\section{Determining constraints}

In order to ensure that results of the optimization have practical application value, it is necessary to set constraints on design variables.

(1) According to the working principle of planar fourbar mechanism, the four-bar mechanism is a doublerocker mechanism, and the length of the connecting rod should meet the geometric conditions, as follow:

$$
l_{23}+l_{34}-l_{45}-l_{25} \leq 0
$$

(2) The boundary constraints of optimized design variables are limited by the upper and lower limits of the design variables according to the overall design plan and design experience: $\pm 50 \mathrm{~mm}$, as is shown in Table 1 .

Table 1 Initial value and optimization range of design variables

\begin{tabular}{|c|c|c|c|}
\hline $\begin{array}{c}\text { Design } \\
\text { variables }\end{array}$ & $\begin{array}{c}\text { Initial } \\
\text { value }\end{array}$ & Minimum & Maximum \\
\hline$x_{1} / m m$ & 2306 & 2256 & 2356 \\
\hline$y_{l} / m m$ & 20930 & 20880 & 20980 \\
\hline$x_{2} / m m$ & 2613 & 2563 & 2663 \\
\hline $\boldsymbol{y}_{2} / \boldsymbol{m m}$ & 23412 & 23362 & 23462 \\
\hline$x_{3} / m m$ & 2190 & 2140 & 2240 \\
\hline$y_{3} / m m$ & 23060 & 23010 & 23110 \\
\hline$x_{4} / m m$ & 2438 & 2388 & 2488 \\
\hline$y_{4} / m m$ & 23031 & 22981 & 23081 \\
\hline$x_{5} / m m$ & 2367 & 2317 & 2417 \\
\hline$y_{s} / m m$ & 23466 & 23416 & 23516 \\
\hline
\end{tabular}

(3) The initial length $\left(l_{12}\right)$ and the maximum stroke distance of the hydraulic cylinder $\left(l_{12}\right)$ should meet the requirements of the manufacturing process and stability of the hydraulic cylinder ${ }^{[5]}$ :

$$
0.54 \leq \frac{l_{12}}{l_{12}} \leq 0.60
$$

\section{Particle swarm algorithm}

\subsection{Introduction of algorithm}

Particle swarm algorithm is a widely used intelligent optimization algorithm, and it simulates the flight rules of birds choosing their own flight direction and flight speed when they are foraging to find the optimal solution ${ }^{[6]}$. Since the method was proposed by Kenendy $\mathrm{J}$ et al. in 1995, it has been successfully applied to practical problems such as multi-objective optimization, neural network training, and signal processing ${ }^{[7]}$. From the previous analysis, it can be seen that the hinge point optimization of the luffing mechanism is a multi-variable and multi-constrained nonlinear problem, which is suitable for solving by the particle swarm algorithm. Figure 3 is a flowchart of particle swarm optimization algorithm.
Based on the previous analysis, the goal of this article is to find the optimal position of the hinge point of the secondary boom luffing cylinder. And the optimal positions of point $1\left(x_{1}, y_{1}\right)$, point $2\left(x_{2}, y_{2}\right)$, point 3 $\left(x_{3}, y_{3}\right)$, point $4\left(x_{4}, y_{4}\right)$, and point $5\left(x_{5}, y_{5}\right)$ can make the maximum force of the luffing cylinder the smallest. It is denoted as a multi-dimensional variable particle, and each particle represents a group of hinge points.

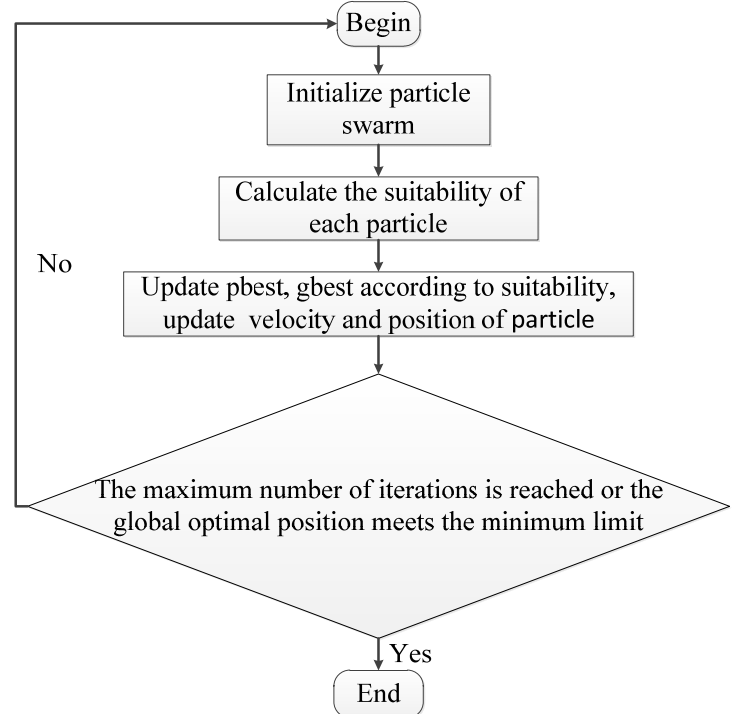

Fig.3. Flow chart of particle swarm optimization

\subsection{Example solution}

(1) Parameter setting of particle swarm algorithm The parameters to be set for the algorithm mainly include: number of particles $(M)$, the particle speed $(v)$, and maximum number of iterations of the program $(k)$. The number of particles will affect the search ability and the amount of calculation of the algorithm. According to the optimization problem in this paper, we set it as 500 ( $M=500)$. The particle speed needs to be selected reasonably, too large may roughly miss the optimal solution, and too small will increase the amount of calculation. Each dimension of $v_{\max }$ is generally $10 \%-20 \%$ of the corresponding dimension search space ${ }^{[8]}$, and the maximum number of iterations is $k=300$.

(2) Initialization of particle position and velocity

Randomly initializing the particles in the feasible region, and the initial speed is the minimum $\left(v_{\min }\right)$ speed of the particle swarm. Then selecting the initial value of the hinge position as the initial position, that is $\left(x_{1}, y_{1}, x_{2}, y_{2}, x_{3}, y_{3}, x_{4}, y_{4}, x_{5}, y_{5}\right)$.

(3) Calculating fitness value

From the previous analysis, we can see that the objective function is the force of the luffing cylinder and is related to the position of each hinge point. So the fitness function of the particle is:

$$
F_{1}=\left(x_{1}, y_{1}, x_{2}, y_{2}, x_{3}, y_{3}, x_{4}, y_{4}, x_{5}, y_{5}\right)
$$

(4) The position and velocity of particles are updated according to the fitness value, and the iterative formulas are as follows ${ }^{[9]}$ : 


$$
\begin{gathered}
v_{i+1}(t+1)=w v_{i}(t)+c_{1} r_{1}\left(\text { pbest }_{i}(t)-x_{i}(t)\right) \\
+c_{2} r_{2}\left(\text { gbest }-x_{i}(t)\right) \\
x_{i+1}(t+1)=x_{i}(t)+v_{i+1}(\mathrm{t}+1)
\end{gathered}
$$

In formula, $w$ is inertia weight coefficient. The larger $w$ is conducive to the global solution, while the smaller $w$ is more conducive to improving the local solution. After research, the inertia weight coefficient of this article is $w=0.8 ; c_{1}$ and $c_{2}$ are learning factors, which can be obtained from reference ${ }^{[10]}, c_{1}=c_{2}=0.5 ; i$ is the number of iterations; pbest $_{i}$ is the optimal value of the ith particle; $x_{i}$ and $v_{i}$ are the position and velocity of the i-th particle respectively; $r_{1}, r_{2} \in[0,1]$.

(5) Determining whether the boundary conditions are met

\section{Optimization analysis}

Based on the actual engineering conditions, the objective function is optimized by particle swarm algorithm and Matlab, and the optimized hinge coordinates are obtained, as is shown in Table 2, which is the hinge coordinates before and after optimization.

Table 2 Optimization result of hinge position

\begin{tabular}{|c|c|c|}
\hline $\begin{array}{c}\text { Design } \\
\text { variables }\end{array}$ & $\begin{array}{c}\text { Before the } \\
\text { optimization }\end{array}$ & $\begin{array}{c}\text { After the } \\
\text { optimization }\end{array}$ \\
\hline $\boldsymbol{x}_{\boldsymbol{1}} / \boldsymbol{m} \boldsymbol{m}$ & 2306 & 2304 \\
\hline $\boldsymbol{y}_{1} / \boldsymbol{m} \boldsymbol{m}$ & 20930 & 20946 \\
\hline $\boldsymbol{x}_{2} / \boldsymbol{m} \boldsymbol{m}$ & 2613 & 2643 \\
\hline $\boldsymbol{y}_{2} / \boldsymbol{m} \boldsymbol{m}$ & 23412 & 23398 \\
\hline $\boldsymbol{x}_{3} / \boldsymbol{m} \boldsymbol{m}$ & 2190 & 2145 \\
\hline $\boldsymbol{y}_{3} / \boldsymbol{m} \boldsymbol{m}$ & 23060 & 23069 \\
\hline $\boldsymbol{x}_{4} / \boldsymbol{m} \boldsymbol{m}$ & 2438 & 2454 \\
\hline $\boldsymbol{y}_{4} / \boldsymbol{m} \boldsymbol{m}$ & 23031 & 23069 \\
\hline $\boldsymbol{x}_{5} / \boldsymbol{m} \boldsymbol{m}$ & 2367 & 2363 \\
\hline $\boldsymbol{y}_{5} / \boldsymbol{m} \boldsymbol{m}$ & 23466 & 23483 \\
\hline$F / N$ & 16827 & 13688 \\
\hline
\end{tabular}

It can be seen from table 2 that after optimization, the maximum working force of luffing cylinder is reduced by about $18.9 \%$ under dangerous working conditions, which has an important impact on improving the stability of hydraulic cylinder and the strength of luffing connecting rod and hinge points.

\section{Conclusion}

In this paper, by establishing the mechanical model and mathematical model of luffing mechanism and combining with the actual constraints of boom system, then the objective function is optimized by particle swarm optimization algorithm. The analysis results show that the maximum force of luffing cylinder can be greatly reduced by establishing luffing mechanism according to the optimized hinge point position, which is of great significance to improve the stability of boom system. In the optimization application of practical construction machinery, more actual conditions should be considered, such as friction between telescopic structures, rigidity of linkage mechanism, etc., which can greatly improve the accuracy of optimization results. In addition, this optimization method based on particle swarm optimization can also be extended to other similar structures of construction machinery's optimization design.

\section{Acknowledgments}

This work is supported by the Postgraduate Research and Innovation Project of Jiangsu Normal University (2019XKT162).

\section{References}

1. Li, J., Song, X.G., Han, Z.T., et al. (2017) Optimization analysis of the hinge point of four link luffing system. Construction Machinery, 3: 65-68.

2. Liu, Y.B., Zhang, Y.J., Liu, P. (2017) Strength analysis of boom structure of rotary drilling rig. Modern Manufacturing Technology and Equipment, 12: 107-109.

3. Hu, J.P., Li, K.J. (2016) Dynamics model of mechanical-hydraulic coupling of auger driller during luffing motion by bond graph. Journal of Central South University (Science and Technology), 2: 495-502.

4. Xu, Y.C., Zhang, X., Cui Z.J. (2018) Performance Optimization research of lorry-mounted crane luffing hydraulic system. Chinese Hydraulics \& Pneumatics, 7: 101-104.

5. Li, F., Guo, J.J., Ge, B.J. (2016) Optimization and simulation analysis of crane luffing mechanism based on Matlab and ADAMS. Hoisting and Conveying Machinery, 2: 55-58.

6. Liu, Y.M., Gao, S.Y. (2019) An improved particle swarm optimization algorithm and its algorithm test. Mathematics in Practice and Theory, 9: 237-247.

7. Zhao, N.G., Deng, J.S. (2015) Review of particle swarm optimization. Science and Technology Innovation Herald, 26: 216-217.

8. Bonabeau, E., Dorigo, M., Theraulaz, G. (1999) Swarm intelligence: from natural to artificial systems. Oxford University Press, New York.

9. Xu, C.D., Chen C. (2013) A particle swarm optimization algorithm of adaptive dynamic control parameter. Computer Engineering, 10: 203-207

10. Zhang, X.L., Liu, L.Q. (2012) Intelligent optimization algorithm and its application in mechanical engineering. National Defense Industry Press, Beijing. 